\title{
Application of dexmedetomidine-assisted intravertebral anesthesia in hip replacement and its influence on T-lymphocyte subsets
}

\author{
YUEXIN XU and XIAOXUAN DU \\ Department of Anesthesiology, The Sixth Affiliated Hospital of The Sixth Clinical Medical School of \\ Xinjiang Medical University, Urumqi, Xinjiang 830002, P.R. China
}

Received June 24, 2019; Accepted December 2, 2019

DOI: $10.3892 /$ etm.2020.8869

\begin{abstract}
Application of dexmedetomidine-assisted intravertebral anesthesia for elderly patients with hip replacement and its influences on T-lymphocyte subsets in peripheral blood were assessed. Eighty-six patients undergoing intravertebral anesthesia in hip replacement were treated as group A, and one hundred patients undergoing intravertebral anesthesia combined with dexmedetomidine were treated as group B. Hemodynamic changes in both groups were compared $5 \mathrm{~min}$ before anesthesia (T0), immediately after skin incision (T1) and after surgery (T2). General operation conditions of patients in both groups were recorded. T-lymphocyte subsets, interleukin-6 (IL-6), tumor necrosis factor- $\alpha$ (TNF- $\alpha$ ), visual analogue scale (VAS) pain scores and mini-mental state examination (MMSE) cognitive function changes before surgery and $24 \mathrm{~h}$ after surgery were compared between the groups, and the incidence of complications in both groups after $24 \mathrm{~h}$ was recorded. The recovery time of patients in group $\mathrm{B}$ was shorter than that of group $\mathrm{A}(\mathrm{P}<0.05)$. Changes of systolic blood pressure (SBP), diastolic blood pressure (DBP) and heart rate fluctuations in group $B$ were lower than those in group $\mathrm{A}(\mathrm{P}<0.05)$. At $24 \mathrm{~h}$ after surgery, VAS scores of group $\mathrm{B}$ were lower than those of group A $(\mathrm{P}<0.05)$; levels of IL-6 and TNF- $\alpha$ were lower than those of group A $(\mathrm{P}<0.05)$; $\mathrm{CD}^{+}$cells,
\end{abstract}

Correspondence to: Dr Xiaoxuan Du, Department of Anesthesiology, The Sixth Affiliated Hospital of The Sixth Clinical Medical School of Xinjiang Medical University, 39 Wuxing South Road, Urumqi, Xinjiang 830002, P.R. China

E-mail: dtxv95@163.com

Abbreviations: ASA grading, American Standards Association Classification; BIS, bispectral index; ELISA, enzyme-linked immunosorbent assay; VAS grading, visual analogue scale; MMSE grading, mini-mental state examination; IL-6, interleukin-6; TNF- $\alpha$, tumor necrosis factor- $\alpha$; SBP, systolic blood pressure; DBP, diastolic blood pressure; HR, heart rate; POCD, postoperative cognitive dysfunction

Key words: dexmedetomidine, intravertebral anesthesia, hip replacement, T-lymphocyte subsets
$\mathrm{CD}^{+}$cells, $\mathrm{CD}^{+}$cells, and CD4/CD8 ratio were higher than those of group $\mathrm{A}(\mathrm{P}<0.05)$, and MMSE score was higher than that of group $\mathrm{A}(\mathrm{P}<0.05)$. The incidence of gastrointestinal reactions and postoperative cognitive dysfunction (POCD) in group $\mathrm{B}$ was lower than that in group $\mathrm{A}(\mathrm{P}<0.05)$. In conclusion, administration of dexmedetomidine can effectively shorten the recovery time of patients, stabilize intraoperative hemodynamics of patients, protect immune function, and reduce postoperative pain and POCD occurrence during anesthesia of hip replacement.

\section{Introduction}

The incidence of joint replacement is very high. Over one million of hip and knee replacement operations are performed in the United States each year (1). Due to the aging population and the demand for treatment quality and quality of life, the number of joint replacement operations will further increase (2) in the future. Therefore, risks of anesthesia and death during perioperative period will obviously increase $(3,4)$.

Anesthesia is an essential step in the operation. Appropriate anesthesia method is of decisive significance to maintain vital signs of patients and help them to survive the perioperative period (5). Anesthesia procedure is an independent factor that affects the mortality of elderly orthopedic patients. Peripheral nerve block can reduce the incidence and mortality of perioperative complications $(6,7)$. Lumbar plexus combined with sciatic nerve block anesthesia has advantages of small hemodynamic impact and good postoperative analgesic effects (8). However, if tissue damage during surgery is extensive and often affects adjacent nerves, patients may experience immunosuppression for up to one week, significantly increasing risks of infection and other pathological complications (9). Dexmedetomidine is an $\alpha 2$ adrenergic receptor agonist with high specificity. Besides sedation and abirritation, dexmedetomidine also has anti-sympathetic and anti-anxiety effects (10). In recent years, many studies have reported that dexmedetomidine-assisted anesthesia has good effects on protection of immune function of patients after various surgical treatments. Wang et al (11) reported that the supplement of dexmedetomidine anesthesia in gastrectomy could reduce surgical stimulation and inflammatory response, 
maintain the balance of Th1/Th2, and protect the immune function of patients. Jang et al (12) further analyzed the analgesic effect of dexmedetomidine on immune regulation under pain condition through an animal model. They established a mouse model of formalin-induced pain, and discovered that dexmedetomidine could effectively improve the pain response of formalin-induced pain in mice in acute pain stage 1 and hyperalgesia stage 2 , and inhibit the activation of natural killer cells under pain conditions. Moreover, dexmedetomidine has no toxic effect on splenocytes and can protect immune function more effectively. But there are few reports on protection of immune function of dexmedetomidine in joint replacement, which still needs to be verified.

This study analyzed the application of dexmedetomidine-assisted intravertebral anesthesia in hip replacement and its influence on T-lymphocyte subsets, providing reference for clinical anesthesia treatment.

\section{Patients and methods}

Subjects of study. A total of 186 patients undergoing elective hip replacement surgery from January 2013 to February 2017 in The Sixth Affiliated Hospital of the Sixth Clinical Medical School of Xinjiang Medical University (Urumqi, China) were selected, aged 55-70 years. Patients were divided into two groups according to different anesthesia methods. Patients undergoing intravertebral anesthesia were as group A (86 cases), and patients undergoing intravertebral anesthesia combined with dexmedetomidine were included in group B (100 cases). Inclusion criteria: The patients were unable to relieve hip pain with conservative treatment, and were treated with hip replacement for the first time. The patients were unilateral hip disease and ASA grade I-III. Exclusion criteria: There were serious organic diseases such as heart, lung and liver, uncontrolled hypertension and diabetes, abnormal metabolism of water and electrolytes, osteoporosis, abnormal mental state and inability to communicate, patients with active infection including hip joint. This study was in line with the Helsinki Declaration.

The study was approved by the Ethics Committee of the Sixth Affiliated Hospital of the Sixth Clinical Medical School of Xinjiang Medical University. Patients who participated in this research, signed an informed consent and had complete clinical data.

Anesthesia methods. The patients fasted for $12 \mathrm{~h}$ before surgery and did not take any drugs. All patients received lumbar nerve block anesthesia. Arterial pressure, central venous pressure, electrocardiogram, blood pressure, heart rate, pulse and oxygen protection were monitored. After determining the lumbar nerve location under ultrasound guidance, $25 \mathrm{ml}$ of $0.375 \%$ ropivacaine was injected around it for anesthesia. Intravenous sufentanil $0.35 \mu \mathrm{g} / \mathrm{kg}+$ midazolam $0.05 \mathrm{mg} / \mathrm{kg}$ + vecuronium bromide $0.15 \mathrm{mg} / \mathrm{kg}+$ propofol $1.5 \mathrm{mg} / \mathrm{kg}$ were used for anesthesia induction, remifentanil $0.3 \mu \mathrm{g} / \mathrm{kg} / \mathrm{min}+$ propofol $1.5 \mathrm{mg} / \mathrm{kg} / \mathrm{h}$ + vecuronium bromide $2 \mathrm{mg}$ were used for anesthesia maintenance, and bispectral index (BIS) 40-60 were maintained. Patients in group B were injected $0.6 \mu \mathrm{g} / \mathrm{kg}$ dexmedetomidine intravenously $15 \mathrm{~min}$ before anesthesia induction.
Table I. Ramsay sedation score.

$\begin{array}{ll}1 \text { point } & \text { It is easy to create anxiety and irritability. } \\ 2 \text { points } & \begin{array}{l}\text { Patients are sober, able to cooperate with } \\ \text { medical work, and relatively calm. }\end{array} \\ 3 \text { points } & \begin{array}{l}\text { Sleepiness, only response to commands. } \\ 4 \text { points }\end{array} \\ & \begin{array}{l}\text { Shallow sleep, can be sensitive to mild } \\ \text { shaking or loud sound stimulation. }\end{array} \\ 5 \text { points } & \text { Deep sleep, response to noxious stimulation. }\end{array}$

Observation indicators. Ramsay sedation scores $5 \mathrm{~min}$ before anesthesia (T0), immediately after skin incision (T1) and after surgery (T2) were compared between the groups. General operation conditions of both groups were recorded, including operation time, anesthesia time, bleeding volume and recovery time of infusion volume. Changes of T-lymphocyte subsets before surgery and $24 \mathrm{~h}$ after surgery were measured by flow cytometry. Changes of interleukin-6 (IL-6) and tumor necrosis factor- $\alpha(\mathrm{TNF}-\alpha)$ in the serum of peripheral blood in the two groups before and $24 \mathrm{~h}$ after operation were detected by enzyme-linked immunosorbent assay (ELISA), and hemodynamic changes of T0, T1 and T2 were recorded. visual analogue scale (VAS) scores and mini-mental state examination (MMSE) scores were used to evaluate changes of pain and cognitive function of patients in both groups before surgery and $24 \mathrm{~h}$ after surgery, and the incidence of postoperative complications of patients in both groups was recorded. IL- 6 and TNF- $\alpha$ test kits were all purchased from Wuhan Elabscience Biotechnology Co., Ltd., and the number of kits were E-EL-H0102c and E-EL-H0109c, respectively. CytoFLE S flow cytometry was purchased from Beckman Coulter.

Ramsay sedation score. Two to four is an ideal sedation, less than 2 is ineffective sedation, and more than 4 is excessive sedation (Table I).

Statistical analysis. SPSS 19.0 (Asia Analytics Formerly SPSS China) was used. The measurement data were expressed as $[\mathrm{n}(\%)]$, and comparison of rates between the groups adopted $\chi^{2}$ test. The counting data were expressed as mean \pm SD. Comparison between both groups was conducted by independent-samples t-test, comparison at different time-points in the group was conducted by repeated measures analysis of variance, and back testing was conducted by LSD test. $\mathrm{P}<0.05$ indicates a statistically significant difference.

\section{Results}

General information. There were 86 patients in group A, including 34 male and 52 female patients, with an age of $61.4 \pm 7.3$ years; there were 100 patients in group B, including 47 male and 53 female patients, with an age of $62.9 \pm 7.8$ years. There was no significant difference in sex ratio and age between the groups $(\mathrm{P}>0.05)$. Analysis of results of other data in both groups, such as weight, ASA grading, and history of hypertension, also showed no significant difference $(\mathrm{P}>0.05)$ (Table II). 
Table II. Analysis of general data.

\begin{tabular}{|c|c|c|c|c|}
\hline Patient characteristics & Group A $(n=86)$ & Group B $(n=100)$ & $\chi^{2} / \mathrm{t}$ value & P-value \\
\hline $\operatorname{Sex}[\mathrm{n}(\%)]$ & & & 1.048 & 0.306 \\
\hline Male & $34(39.53)$ & $47(47.00)$ & & \\
\hline Female & $52(60.47)$ & $53(53.00)$ & & \\
\hline Age (years) & $61.4 \pm 7.3$ & $62.9 \pm 7.8$ & 1.347 & 0.180 \\
\hline Weight (kg) & $62.42 \pm 9.17$ & $60.58 \pm 8.24$ & 1.441 & 0.151 \\
\hline ASA classification $[\mathrm{n}(\%)]$ & & & 0.241 & 0.624 \\
\hline $\mathrm{I}$ & $63(73.26)$ & $70(70.00)$ & & \\
\hline II-III & $23(26.74)$ & $30(30.00)$ & & \\
\hline History of hypertension $[\mathrm{n}(\%)]$ & & & 1.048 & 0.306 \\
\hline Yes & $52(60.47)$ & $53(53.00)$ & & \\
\hline No & $34(39.53)$ & $47(47.00)$ & & \\
\hline History of diabetes $[\mathrm{n}(\%)]$ & & & 1.565 & 0.211 \\
\hline Yes & $17(19.77)$ & $13(13.00)$ & & \\
\hline No & $69(80.23)$ & $87(87.00)$ & & \\
\hline Other surgical history $[\mathrm{n}(\%)]$ & & & 0.290 & 0.590 \\
\hline Yes & $20(23.26)$ & $20(20.00)$ & & \\
\hline No & $66(76.74)$ & $80(80.00)$ & & \\
\hline Operative site $[\mathrm{n}(\%)]$ & & & 0.116 & 0.733 \\
\hline Left & $34(39.53)$ & $42(42.00)$ & & \\
\hline Right & $52(60.47)$ & $58(58.00)$ & & \\
\hline Years of education & $11.3 \pm 4.5$ & $12.4 \pm 5.3$ & & \\
\hline
\end{tabular}

Table III. Comparison of Ramsay sedation score of patients between the two groups.

\begin{tabular}{lcccc}
\hline Times & $\begin{array}{c}\text { Group A } \\
(\mathrm{n}=86)\end{array}$ & $\begin{array}{c}\text { Group B } \\
(\mathrm{n}=100)\end{array}$ & t-value & P-value \\
\hline T0 & $2.14 \pm 0.11$ & $2.16 \pm 0.12$ & 1.178 & 0.241 \\
T1 & $3.12 \pm 0.75^{\mathrm{a}}$ & $3.24 \pm 0.63^{\mathrm{a}}$ & 1.186 & 0.237 \\
T2 & $3.26 \pm 0.62^{\mathrm{a}}$ & $3.30 \pm 0.59^{\mathrm{a}}$ & 0.450 & 0.653 \\
\hline
\end{tabular}

${ }^{\mathrm{a}} \mathrm{P}<0.05$ compare with the score at $\mathrm{T} 0$ of the same group.

Comparison of Ramsay sedation score of patients between the groups. Ramsay sedation score represented that there was no statistical difference in Ramsay sedation score of patients between the groups at each time-point ( $>>0.05)$; Ramsay sedation score was higher than that at $\mathrm{T} 1$ and $\mathrm{T} 2(\mathrm{P}<0.05)$, and there was no statistical difference between $\mathrm{T} 1$ and $\mathrm{T} 2$ (P>0.05) (Table III).

Analysis of general conditions of surgery for patients in both groups. Operation time, anesthesia time, hemorrhage volume and infusion volume of both groups had no statistical difference $(\mathrm{P}>0.05)$, but the recovery time of group $\mathrm{B}$ was shorter than that of group $\mathrm{A}(\mathrm{P}<0.05)$ (Fig. 1).

Hemodynamic changes of patients in both groups during surgery. Hemodynamic monitoring results showed that there was no statistical difference in systolic blood pressure (SBP), diastolic blood pressure (DBP) and heart rate between the groups at T0 $(\mathrm{P}>0.05)$. There was no statistical difference in SBP between the groups at T1 $(\mathrm{P}>0.05)$, but DBP and heart rate $(\mathrm{HR})$ in group $\mathrm{B}$ were lower than those in group $\mathrm{A}$ $(\mathrm{P}<0.05)$, while SBP, DBP and heart rate in group $\mathrm{B}$ were lower than those in group A at T2 $(\mathrm{P}<0.05)$. Intra-group comparison results showed that SBP and DBP of patients in both groups at $\mathrm{T} 1$ were higher than those at $\mathrm{T} 0(\mathrm{P}<0.05)$, the heart rate of patients in group $\mathrm{A}$ was also higher than that at T0 $(\mathrm{P}<0.05)$, while patients in group $\mathrm{B}$ had no significant change $(\mathrm{P}>0.05)$. By T2, SBP and DBP of patients in both groups were both lower than those at $\mathrm{T} 1(\mathrm{P}<0.05)$, and the heart rate had no significant changes compared with that at T1 $(\mathrm{P}<0.05)$ (Table IV).

Differences in postoperative VAS scores of patients between the groups. VAS score results indicated that there was no statistically significant difference in VAS score of patients between the groups before surgery $(\mathrm{P}>0.05)$. VAS scores of patients in both groups were significantly reduced $24 \mathrm{~h}$ after surgery $(\mathrm{P}<0.05)$, but those in group $\mathrm{B}$ were lower than those in group $\mathrm{A}(\mathrm{P}<0.05)$ (Fig. 2).

Analysis of changes of inflammatory response related factors after surgery of patients in both groups. The results of ELISA showed that there was no significant difference between the groups in IL-6 and TNF- $\alpha$ before surgery $(\mathrm{P}>0.05)$. Twenty-four hours after surgery, IL- 6 and TNF- $\alpha$ of patients in both groups were higher than those before surgery $(\mathrm{P}<0.05)$, 

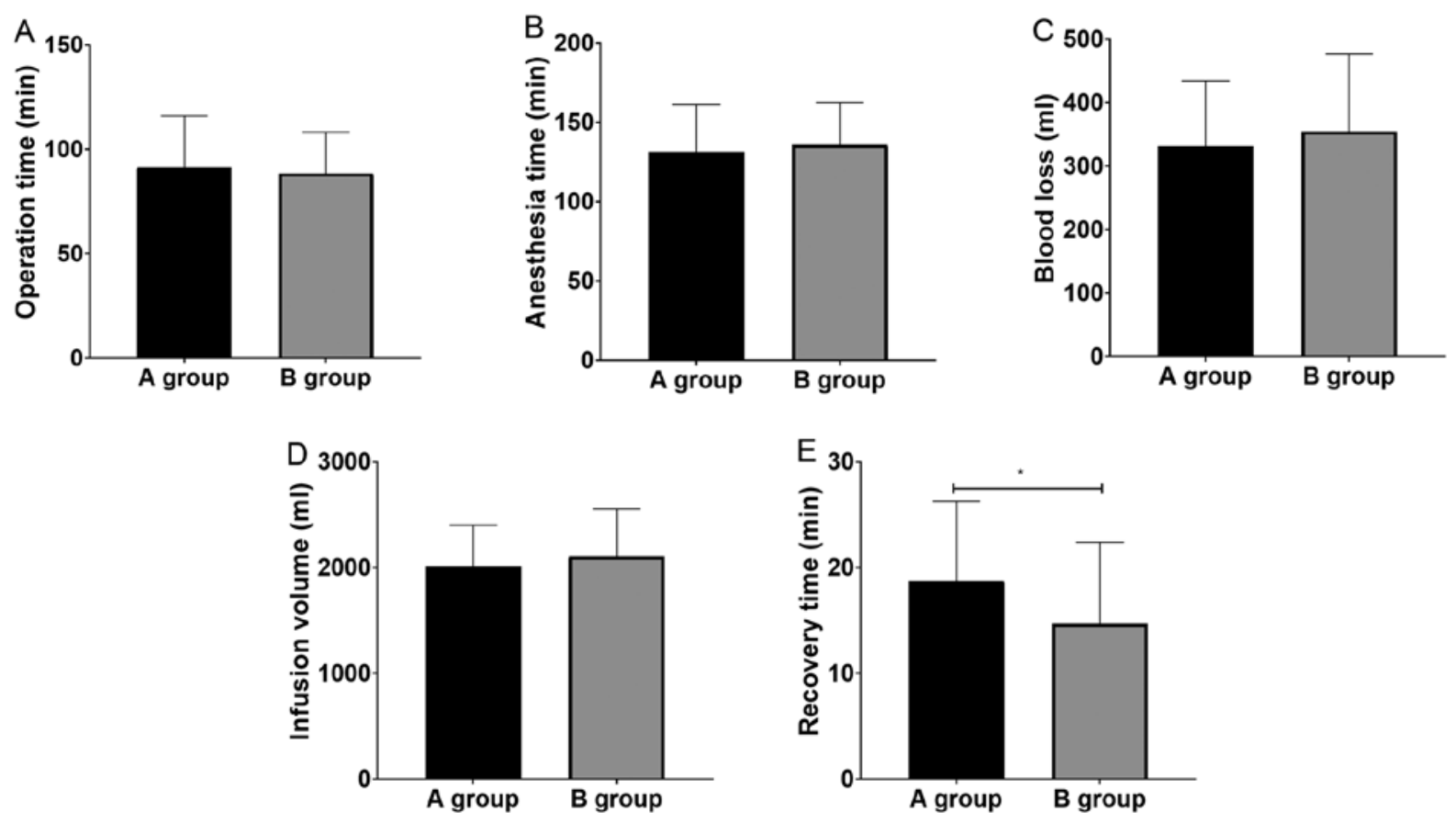

Figure 1. Analysis of the general condition of surgery of patients in both groups. (A) Time of operation; (B) anesthesia time; (C) amount of bleeding; (D) infusion volume; (E) awakening time. ${ }^{\prime \prime} \mathrm{P}<0.05$.

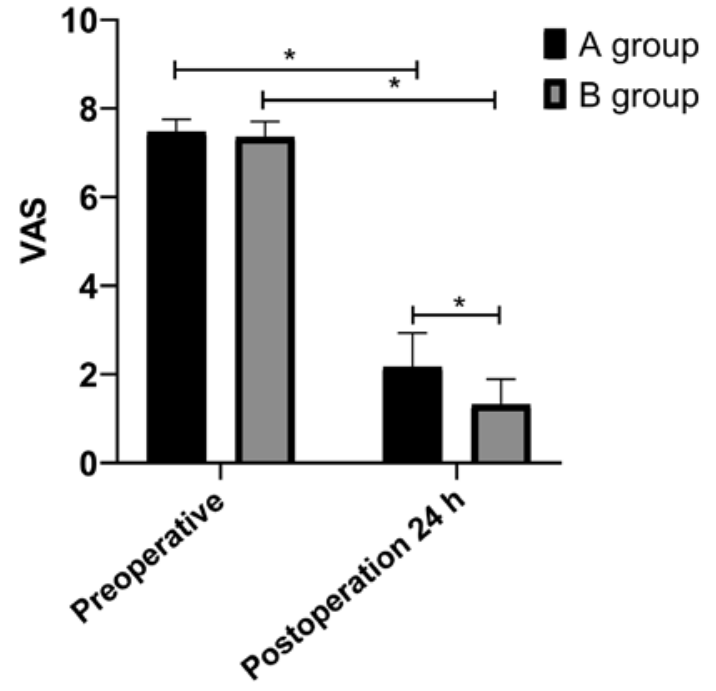

Figure 2. Differences in postoperative VAS scores of patients between the groups. ${ }^{*} \mathrm{P}<0.05$.

but those in group B were lower than those in group A $(\mathrm{P}<0.05)($ Table V).

Analysis on changes of T-lymphocyte subsets of patients in both groups. The results of flow cytometry revealed that $24 \mathrm{~h}$ after surgery, $\mathrm{CD}^{+}$cells, $\mathrm{CD}^{+}{ }^{+}$cells, $\mathrm{CD}^{+}$cells and CD4/CD8 ratio of patients in both groups were lower than those before surgery $(\mathrm{P}<0.05)$, but those in group $\mathrm{B}$ were higher than those in group $\mathrm{A}(\mathrm{P}<0.05)$ (Fig. 3).

Analysis of complications 24 h after surgery. There was no statistical difference in the incidence of vertigo and increase of blood pressure $24 \mathrm{~h}$ after surgery of patients between the groups $(\mathrm{P}>0.05)$, but the incidence of gastrointestinal reaction and postoperative cognitive dysfunction (POCD) in group $\mathrm{B}$ was lower than that in group A $(\mathrm{P}<0.05)$ (Table VI).

Changes of MMSE scores of patients in the groups. MMSE scores displayed that there was no significant difference in MMSE scores of patients between the groups before surgery $(\mathrm{P}>0.05)$. MMSE scores in group $\mathrm{B}$ were significantly higher than those in group A $24 \mathrm{~h}$ after surgery $(\mathrm{P}<0.05)$, but MMSE scores in both groups were lower than those before surgery $(\mathrm{P}<0.05)$ (Fig. 4).

\section{Discussion}

Anesthesia of patients in both groups in this study was good. Ramsay sedation score was between 2 and 4 points. From the results of this study, administration of $0.6 \mu \mathrm{g} / \mathrm{kg}$ dexmedetomidine before anesthesia induction can effectively shorten postoperative recovery time of patients and stabilize their hemodynamic changes during surgery, which was consistent with the results reported in previous studies. Zhou et al (13) reported that administration of dexmedetomidine could stabilize hemodynamics, reduce postoperative recovery time, and also shorten extubation time. Nayagam et al (14) also reported advantages of dexmedetomidine in stabilizing hemodynamics during surgery. Patients with hip joint diseases are often accompanied by unbearable pain $(15,16)$. Even if this situation can be effectively improved after surgery, due to invasive operation and other reasons, patients may still have severe pain after anesthesia, which affects their recovery (17). Dexmedetomidine is a selective $\alpha$ receptor agonist with rapid onset, long duration of motor and sensory block, and can effectively prolong the analgesic time (18). This study indicated that VAS pain score of patients in group B was significantly 
Table IV. Hemodynamic changes of patients in the two groups during operation.

\begin{tabular}{|c|c|c|c|c|}
\hline Hemodynamic changes & Group A $(n=86)$ & Group B $(n=100)$ & t-value & P-value \\
\hline \multicolumn{5}{|l|}{$\mathrm{SBP}(\mathrm{mmHg})$} \\
\hline T0 & $138.47 \pm 10.81$ & $137.82 \pm 10.79$ & 0.409 & 0.683 \\
\hline $\mathrm{T} 1$ & $151.73 \pm 12.38^{\mathrm{a}}$ & $148.86 \pm 12.71^{\mathrm{a}}$ & 1.554 & 0.122 \\
\hline $\mathrm{T} 2$ & $147.28 \pm 13.75^{\mathrm{a}, \mathrm{b}}$ & $125.73 \pm 14.61^{\mathrm{a}, \mathrm{b}}$ & 10.305 & $<0.001$ \\
\hline \multicolumn{5}{|l|}{$\mathrm{DBP}(\mathrm{mmHg})$} \\
\hline T0 & $85.42 \pm 6.71$ & $85.38 \pm 7.33$ & 0.048 & 0.962 \\
\hline $\mathrm{T} 1$ & $104.83 \pm 7.48^{\mathrm{a}}$ & $95.67 \pm 9.42^{\mathrm{a}}$ & 7.261 & $<0.001$ \\
\hline $\mathrm{T} 2$ & $95.32 \pm 10.85^{\mathrm{a}, \mathrm{b}}$ & $83.42 \pm 10.26^{\mathrm{a}, \mathrm{b}}$ & 7.680 & $<0.001$ \\
\hline \multicolumn{5}{|l|}{ HR (times/min) } \\
\hline T0 & $85.46 \pm 5.15$ & $85.49 \pm 5.07$ & 0.040 & 0.968 \\
\hline $\mathrm{T} 1$ & $98.85 \pm 11.52^{\mathrm{a}}$ & $86.83 \pm 5.26^{\mathrm{a}}$ & 9.364 & $<0.001$ \\
\hline $\mathrm{T} 2$ & $97.43 \pm 10.35^{\mathrm{a}}$ & $85.76 \pm 8.73^{\mathrm{a}}$ & 8.342 & $<0.001$ \\
\hline
\end{tabular}

${ }^{\mathrm{a}} \mathrm{P}<0.05$ compared with $\mathrm{T} 0$ of the same group; ${ }^{\mathrm{b}} \mathrm{P}<0.05$ compared with $\mathrm{T} 1$ of the same group. $\mathrm{SBP}$, systolic blood pressure; $\mathrm{DBP}$, diastolic blood pressure; HR, heart rate.
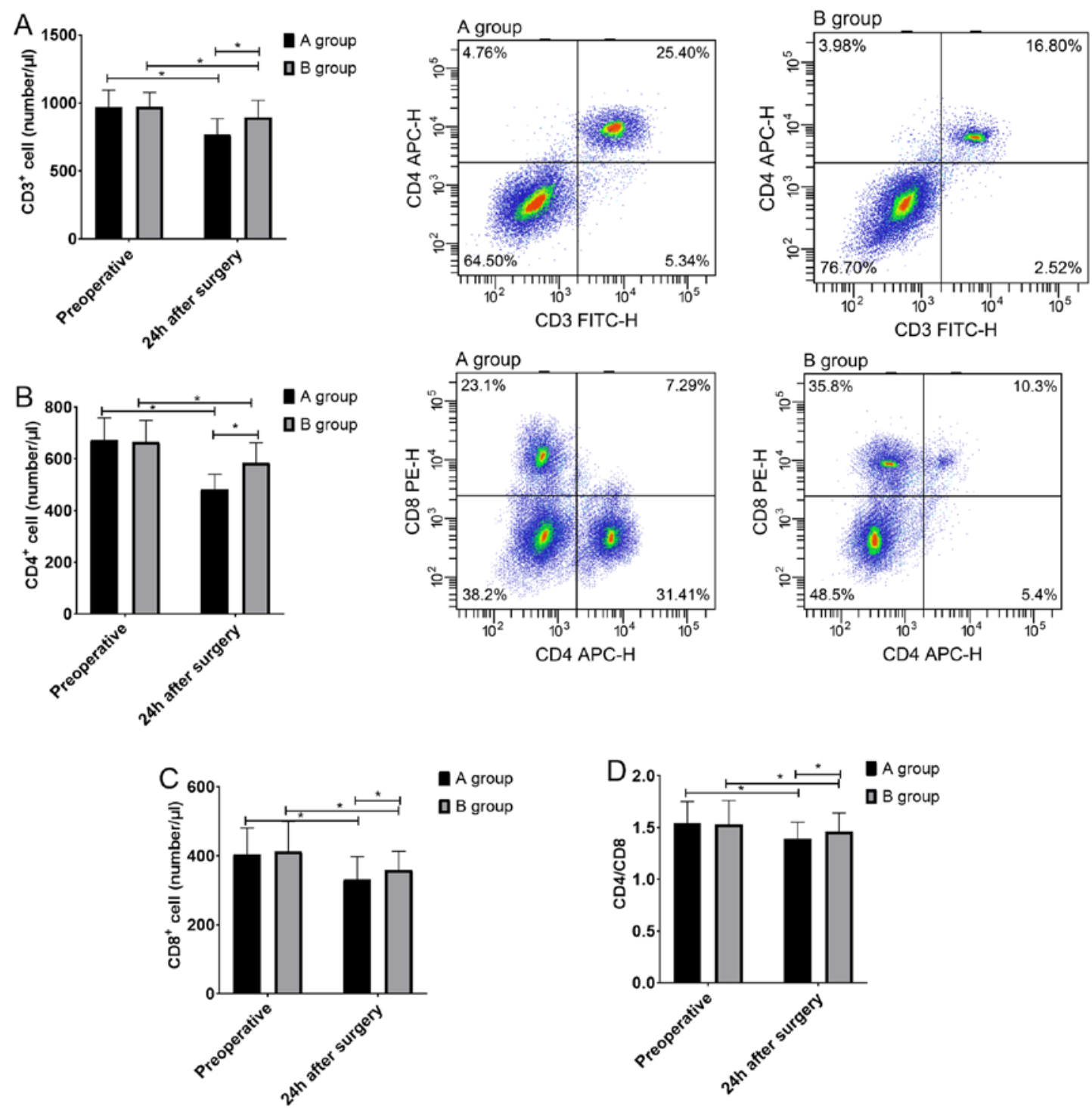

Figure 3. Analysis of changes in T-lymphocyte subsets of patients in both groups. (A) $\mathrm{CD}^{+}$cell levels in both groups; (B) $\mathrm{CD} 4^{+}$cell levels in both groups; (C) $\mathrm{CD} 8{ }^{+}$cell levels in both groups; (D) CD4/CD8 ratio of patients between the groups. ${ }^{*} \mathrm{P}<0.05$. 
Table V. Analysis on changes of inflammatory response related factors after operation of patients in the two groups (pg/ml).

\begin{tabular}{|c|c|c|c|c|}
\hline Inflammatory factors & Group A $(n=86)$ & Group B $(n=100)$ & t-value & P-value \\
\hline \multicolumn{5}{|l|}{ IL-6 } \\
\hline Before operation & $25.22 \pm 4.29$ & $25.38 \pm 4.32$ & 0.253 & 0.801 \\
\hline $24 \mathrm{~h}$ after operation & $40.13 \pm 5.25^{\mathrm{a}}$ & $32.27 \pm 4.88^{\mathrm{a}}$ & 10.574 & $<0.001$ \\
\hline \multicolumn{5}{|l|}{ TNF- $\alpha$} \\
\hline Before operation & $1.58 \pm 0.23$ & $1.51 \pm 0.28$ & 1.844 & 0.067 \\
\hline $24 \mathrm{~h}$ after operation & $3.79 \pm 1.03^{\mathrm{a}}$ & $2.22 \pm 0.83^{\mathrm{a}}$ & 11.507 & $<0.001$ \\
\hline
\end{tabular}

${ }^{\mathrm{a}} \mathrm{P}<0.05$ compared with the same group before operation. $\mathrm{N}$, number of patients. IL-6, interleukin-6; TNF- $\alpha$, tumor necrosis factor- $\alpha$.

Table VI. Analysis of complications $24 \mathrm{~h}$ after operation.

\begin{tabular}{|c|c|c|c|c|}
\hline Complication & Group A $(n=86)$ & Group B $(n=100)$ & $\mathrm{Z}$ value & P-value \\
\hline Gastrointestinal reaction & $8(9.3)$ & $1(1.00)$ & 2.288 & 0.022 \\
\hline Vertigo & $6(6.98)$ & $2(2.00)$ & 1.306 & 0.192 \\
\hline Increase of blood pressure & $6(6.98)$ & $4(4.00)$ & 0.571 & 0.568 \\
\hline POCD & $14(16.28)$ & $6(6.00)$ & 2.019 & 0.044 \\
\hline
\end{tabular}

POCD, postoperative cognitive dysfunction.

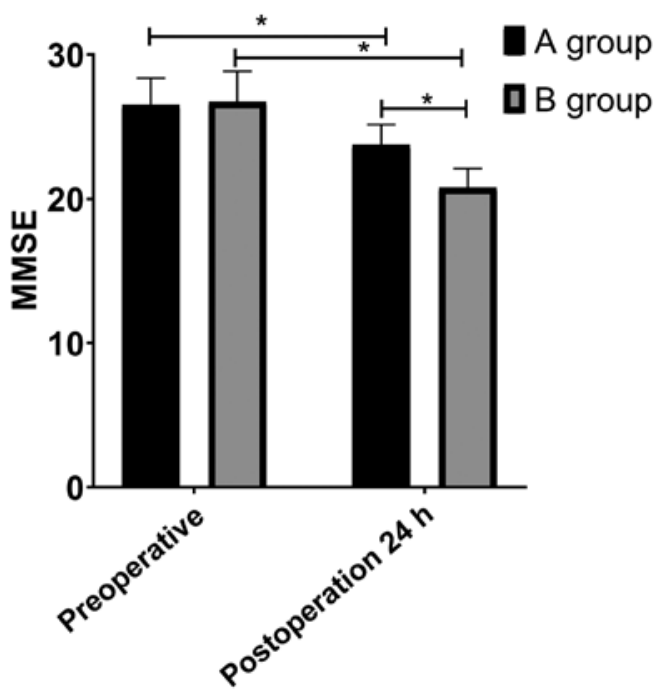

Figure 4. Differences in MMSE scores of patients between the groups after surgery. ${ }^{*} \mathrm{P}<0.05$. MMSE, mini-mental state examination.

lower than that of patients in group A $24 \mathrm{~h}$ after surgery, which also reflected advantages of dexmedetomidine in analgesia. There are similar reports in some studies $(19,20)$ stating that dexmedetomidine can effectively improve postoperative pain of patients.

Increased inflammatory response caused by surgical stress is an important cause of postoperative pain in patients (21), and anti-inflammatory therapy is also an important way to relieve their postoperative pain (22). Based on the results of this study, levels of inflammatory factors IL-6 and TNF- $\alpha$ of patients in group B $24 \mathrm{~h}$ after surgery were significantly lower than those in group A, which suggested that dexmedetomidine $0.6 \mu \mathrm{g} / \mathrm{kg}$ before anesthesia induction could also reduce the production of their inflammatory mediators. Dexmedetomidine also played an effective anti-inflammatory role in other surgical treatments. A meta-analysis showed that perioperative addition of dexmedetomidine could significantly reduce levels of serum IL-6, IL- 8 and TNF- $\alpha$ as well as inflammatory response of patients (23). In a study on artificial tooth implantation, a conclusion that dexmedetomidine provided better postoperative analgesia through anti-inflammatory and antioxidant pathways was further put forward (24).

Postoperative pain is an important reason for the decline of patients' immune function, which is an important factor affecting their prognosis after surgery (25). This study showed that $\mathrm{CD}^{+}$cells, $\mathrm{CD} 4^{+}$cells, $\mathrm{CD}^{+}$cells and $\mathrm{CD} 4 / \mathrm{CD} 8$ ratio of patients in group B were higher than those in group A $24 \mathrm{~h}$ after surgery, suggesting that dexmedetomidine had protective effects on their immune function after surgery. There may be two reasons for this. First, dexmedetomidine can relieve postoperative pain of patients, thus improving the inhibition of pain on their immune function. Second, dexmedetomidine can directly reduce the inhibition of surgery on patients' immune function. Many reports have showed improvement of dexmedetomidine on patients' postoperative immune function. Wang et al (11) reported that dexmedetomidine could reduce the pressure of radical operation for stomach cancer, maintain Th1/Th2 balance, reduce inflammatory reaction and play an immune protective role. Yang et al (26) also reported that intravenous dexmedetomidine could significantly reduce the inhibition of cellular immune function in patients undergoing radical mastectomy, which was of great significance to 
maintain and improve the immune function of the body, as well as their postoperative rehabilitation and prognosis.

We analyzed the safety of dexmedetomidine application in hip replacement. The results showed that gastrointestinal reaction and POCD incidence rate of patients in group $B$ were lower than those in group A, which was also reported in some other studies. As a supplement to peripheral nerve block, dexmedetomidine sedation during operation can reduce the incidence of postoperative psychosis in patients with hip replacement and is conducive to reducing the incidence of early POCD $(27,28)$. This may be related to the anti-inflammatory effects of dexmedetomidine. Li et al (29) reported that the use of dexmedetomidine to reduce the incidence rate of early POCD during anesthesia of laparoscopic cholecystectomy might be realized through the mechanism of reducing the level of inflammatory response. Similar conclusions were also reported in the study by Chen et al (30). A meta-analysis also revealed that postoperative psychosis and POCD were indeed related to the concentration of inflammatory markers in peripheral blood and cerebrospinal fluid, such as CRP and IL-6, which played a certain role in postoperative psychosis and POCD (31). Therefore, the safety of dexmedetomidine in hip replacement could be assured. However, the effect of dextromethopyrimidine might be different between the sexes. Jang et al (32) analyzed and found that dexmedetomidine accelerated the extinction of fear memory and reduced anxiety in rats, but it was more effective on female rats than male rats. Li et al (33) reported that the effect of dexmedetomidine on acute postoperative pain in male patients is better than that in female patients. Thus, further analysis is required on this.

In conclusion, dexmedetomidine administration during anesthesia for patients with hip replacement can effectively shorten the recovery time, stabilize the intraoperative hemodynamics, protect the immune function, and reduce postoperative pain and POCD occurrence rate, which may be related to anti-inflammatory effects of dexmedetomidine.

\section{Acknowledgements}

Not applicable.

\section{Funding}

This study is funded by the project 'A new mechanism of dexmedetomidine regulating IL-17A expression in subacute phase inflammatory response to protect organs from injury' (item no. 2017D01C264).

\section{Availability of data and materials}

The datasets used and/or analyzed during the current study are available from the corresponding author on reasonable request.

\section{Authors' contributions}

YX wrote the manuscript, interpreted and analyzed the patient data. XD performed flow cytometry and ELISA, and was responsible for observation indicators analysis. Both authors read and approved the final manuscript.

\section{Ethics approval and consent to participate}

The study was approved by the Ethics Committee of the Sixth Affiliated Hospital of the Sixth Clinical Medical School of Xinjiang Medical University (Urumqi, China). Patients who participated in this research, signed an informed consent and had complete clinical data.

\section{Patient consent for publication}

Not applicable.

\section{Competing interests}

The authors declare that they have no competing interests.

\section{References}

1. Kremers HM, Larson DR, Crowson CS, Kremers WK, Washington RE, Steiner CA, Jiranek WA and Berry DJ: Prevalence of total hip and knee replacement in the United States. J Bone Joint Surg Am 97: 1386-1397, 2015.

2. Kurtz SM, Lau E, Ong K, Zhao K, Kelly M and Bozic KJ: Future young patient demand for primary and revision joint replacement: National projections from 2010 to 2030. Clin Orthop Relat Res 467: 2606-2612, 2009.

3. Liu XW, Zi Y, Xiang LB and Wang Y: Total hip arthroplasty: Areview of advances, advantages and limitations. Int J Clin Exp Med 8: 27-36, 2015.

4. Bilsel K, Erdil M, Gulabi D, Elmadag M, Cengiz O and Sen C: Factors affecting mortality after hip fracture surgery: A retrospective analysis of 578 patients. Eur J Orthop Surg Traumatol 23: 895-900, 2013.

5. Kadry B, Feaster WW, Macario A and Ehrenfeld JM: Anesthesia information management systems: Past, present, and future of anesthesia records. Mt Sinai J Med 79: 154-165, 2012

6. Flack S and Anderson C: Ultrasound guided lower extremity blocks. Paediatr Anaesth 22: 72-80, 2012.

7. Karaca S, Ayhan E, Kesmezacar H and Uysal O: Hip fracture mortality: Is it affected by anesthesia techniques? Anesthesiol Res Pract 2012: 708754, 2012.

8. Shi ZY, Jiang CN and Shao G: Application of lower limb nerve block combined with slow induction of light general anesthesia and tracheal induction in elderly hip surgery. Medicine (Baltimore) 97: e12581, 2018.

9. Gu CY, Zhang J, Qian YN and Tang QF: Effects of epidural anesthesia and postoperative epidural analgesia on immune function in esophageal carcinoma patients undergoing thoracic surgery. Mol Clin Oncol 3: 190-196, 2015.

10. Suthar O, Sethi P and Sharma UD: Comparison of dexmedetomidine and clonidine as an adjuvant to intrathecal bupivacaine in lower limb surgery: A randomised, double-blind, placebo controlled trial. Anaesth Pain Intensive Care 18: 149-154, 2015.

11. Wang Y, Xu X, Liu H and Ji F: Effects of dexmedetomidine on patients undergoing radical gastrectomy. J Surg Res 194: 147-153, 2015.

12. Jang Y, Yeom MY, Kang ES, Kang JW and Song HK: The antinociceptive effect of dexmedetomidine modulates spleen cell immunity in mice. Int J Med Sci 11: 226-233, 2014.

13. Zhou J, Wang J and Meng F: The use of dexmedetomidine in aged patients with total hip replacement surgery under general anesthesia: Changes in hemodynamics, cerebral state index and wakening quality. Afr J Pharm Pharmacol 6: 1833-1836, 2012.

14. Nayagam HA, Singh NR and Singh HS: A prospective randomised double blind study of intrathecal fentanyl and dexmedetomidine added to low dose bupivacaine for spinal anesthesia for lower abdominal surgeries. Indian J Anaesth 58: 430-435, 2014.

15. Park SH, Kim AR and Lee HS: Effects of short-term corrective exercise on pain, hip joint range of motion and trunk muscle strength of a patient with anterior pelvic tilt: A case study. Off J Korean Acad Kinesiol 18: 85-93, 2016. 
16. Iidaka T, Muraki S, Oka H, Kodama R, Tanaka S, Kawaguchi H, Nakamura K, Akune T and Yoshimura N: Radiographic measurements of the hip joint and their associations with hip pain in Japanese men and women: The Research on Osteoarthritis/osteoporosis Against Disability (ROAD) study. Osteoarthritis Cartilage 25: 2072-2079, 2017.

17. Wylde V, Sayers A, Lenguerrand E, Gooberman-Hill R, Pyke M, Beswick AD, Dieppe P and Blom AW: Preoperative widespread pain sensitization and chronic pain after hip and knee replacement: a cohort analysis. Pain 156: 47-54, 2015.

18. Hua X, Hu Y, Chen D, Xiao Y and Luo L: Efficacy and safety of ultrasound-guided fascia iliaca compartment block using dexmedetomidine combined with ropivacaine in aged patients undergoing hip replacement. Int J Clin Exp Med 10: 16484-16491, 2017.

19. Wu ZL, Zhou ZF, Xu LX and She SZ: Effect of dexmedetomidine on patient-controlled intravenous analgesia with fentanyl in elderly patients after total hip replacement. Nan Fang Yi Ke Da Xue Xue Bao 31: 701-704, 2011 (In Chinese).

20. Peng K, Liu HY, Wu SR, Cheng H and Ji FH: Effects of combining dexmedetomidine and opioids for postoperative intravenous patient-controlled analgesia. Clin J Pain 31: 1097-1104, 2015.

21. Reddi D: Preventing chronic postoperative pain. Anaesthesia 71 (Suppl 1): 64-71, 2016

22. Zhang Z, Xu H, Zhang Y, Li W, Yang Y, Han T, Wei Z, Xu X and Gao J: Nonsteroidal anti-inflammatory drugs for postoperative pain control after lumbar spine surgery: A meta-analysis of randomized controlled trials. J Clin Anesth 43: 84-89, 2017.

23. Li B, Li Y, Tian S, Wang H, Wu H, Zhang A and Gao C: Anti-inflammatory effects of perioperative dexmedetomidine administered as an adjunct to general anesthesia: A meta-analysis. Sci Rep 5: 12342, 2015.

24. Li S, Yang Y, Yu C, Yao Y, Wu Y, Qian L and Cheung CW: Dexmedetomidine analgesia effects in patients undergoing dental implant surgery and its impact on postoperative inflammatory and oxidative stress. Oxid Med Cell Longev 2015: 186736, 2015.

25. Beilin B, Shavit Y, Trabekin E, Mordashev B, Mayburd E, Zeidel A and Bessler $\mathrm{H}$ : The effects of postoperative pain management on immune response to surgery. Anesth Analg 97: $822-827,2003$
26. Yang XH, Bai Q, Lv MM, Fu HG, Dong TL and Zhou Z: Effect of dexmedetomidine on immune function of patients undergoing radical mastectomy: A double blind and placebo control study. Eur Rev Med Pharmacol Sci 21: 1112-1116, 2017.

27. Mei B, Meng G, Xu G, Cheng X, Chen S, Zhang Y, Zhang M, Liu $X$ and Gu E: Intraoperative sedation with dexmedetomidine is superior to propofol for elderly patients undergoing hip arthroplasty. Clin J Pain 34: 811-817, 2018.

28. Liu Y, Ma L, Gao M, Guo W and Ma Y: Dexmedetomidine reduces postoperative delirium after joint replacement in elderly patients with mild cognitive impairment. Aging Clin Exp Res 28: 729-736, 2016.

29. Li Y, He R, Chen S and Qu Y: Effect of dexmedetomidine on early postoperative cognitive dysfunction and peri-operative inflammation in elderly patients undergoing laparoscopic cholecystectomy. Exp Ther Med 10: 1635-1642, 2015.

30. Chen W, Liu B, Zhang F, Xue P, Cui R and Lei W: The effects of dexmedetomidine on post-operative cognitive dysfunction and inflammatory factors in senile patients. Int J Clin Exp Med 8: 4601-4605, 2015.

31. Liu X, Yu Y and Zhu S: Inflammatory markers in postoperative delirium (POD) and cognitive dysfunction (POCD): A meta-analysis of observational studies. PLoS One 13: e0195659, 2018.

32. Jang M, Jung T, Kim SH and Noh J: Sex differential effect of dexmedetomidine on fear memory extinction and anxiety behavior in adolescent rats. Neurosci Res 149: 29-37, 2019.

33. Li YY, Ge DJ, Li JY and Qi B: Sex differences in the morphine-sparing effects of intraoperative dexmedetomidine in patient-controlled analgesia following general anesthesia: A consort-prospective, randomized, controlled clinical trial. Medicine (Baltimore) 95: e3619, 2016. 